\title{
IONIZATION AND RESONANCE POTENTIALS FOR ELECTRONS IN VAPORS OF LEAD AND CALCIUM
}

\author{
By F. L. Mohler, Paul D. Foote, and H. F. Stimson
}

\section{CONTENTS}

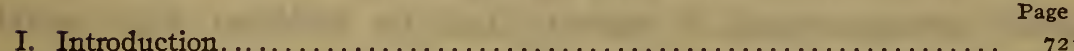

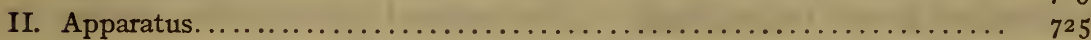

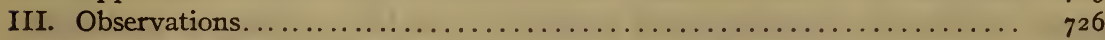

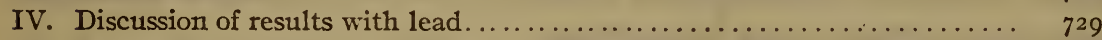

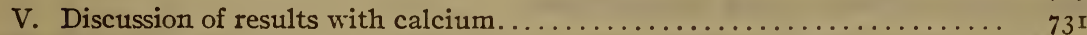

VI. Summary........................................ ${ }_{73} 6$

\section{INTRODUCTION}

Previous papers ${ }^{1}$ have discussed measurements made in this laboratory of ionization and resonance potentials of a number of metals.

A continuation of this work has led to satisfactory results for lead and calcium.

The method of measurement employed has been described in detail elsewhere. The metal is boiled at low pressure in a vacuum tube containing a Wehnelt cathode surrounded by a cylindrical grid and plate. Between the cathode and grid is placed a variable potential to accelerate the electron current from the cathode, while a small retarding field is fixed between the grid and plate. Measurement of the total current, leaving the cathode as the accelerating potential is increased, shows a sudden increase in the current when the ionization point is reached on account of the direct effect of ionization and the indirect effect of positive charges on the electric field. The "partial current" reaching the plate against a small retarding field decreases when the electrons near the grid lose nearly all their velocity by inelastic impact with vapor molecules. The curve of "partial current" versus accelerating potential shows a series of drops in the current at equal voltage intervals. This interval is equal to the resonance potential, and the distance of the first drop from the origin is the resonance potential, minus the initial velocity in volts, of electrons leaving the cathode. The initial velocity correction added to the applied potential at the ionization point gives the ionization potential.

1 Tate and Foote, Phil. Mag., 36, p. 64; 1918. Bur. Stds. Sci. Pap. 317. Foote and Mohler, Phil. Mag., 37, p. 33; 1919. Jour. Wash. Acad. Sci., 8, p. 513; 1918. Foote and Rognley and Mohler, Phys. Rev., 13, p. 59; 1919 . 
This interpretation of the partial-current curves is based on two assumptions:

(a) That, when the velocity of an electron is less than that corresponding to the resonance potential, collisions are elastic.

(b) That, when equal to or greater than the resonance potential, the velocity lost at collision is equal to the resonance potential.

The first assumption is almost certainly justified, although no direct measurements of velocity lost by collision with metal molecules have been made. The second assumption seems to agree with all experimental results, but the evidence available does not exclude other hypotheses.

If the transfer of energy from an electron in passing through an atom is analogous to mechanical resonance phenomena, an electron with velocity equal to or twice or three times the resonance velocity will lose some kinetic energy in passing through, thus giving rise to the successive inflections in the current curve. These inflections in this case would be much more marked if the retarding field between the grid and the plate were nearly as large as the accelerating field between the cathode and grid, for most of the electrons would lose only a small part of their velocity. Experiment, however, shows that the partial-current curve is not noticeably changed by increasing the retarding field above a fraction of a volt.

An entirely different hypothesis to explain the decrease in the partial current at the resonance potential is that radiation at this voltage causes a photo-electric current between the plate and grid opposite in direction to the original electron current. The experiments of Davis and Goucher ${ }^{2}$ with mercury vapor prove that such a current exists and increases by steps equal to the resonance potential. However, experiments in this laboratory with an ionization chamber of the type used by Davis and Goucher show that when the partial current gives strong inflection and full scale deflection on a shunted galvanometer the photo-electric current is immeasurably small. The effect is probably of negligible importance in all our experiments.

Another possible explanation of the inflections suggested by the work of Akesson ${ }^{3}$ is that electrons with velocity several times the resonance potential may lose several "quanta" of energy at one collision. Akesson's conclusions are based on experiments with nonmetallic gases, and the authors doubt whether he has conclusively proven this important point. A quantitative study 
of partial and total currents in a metallic vapor at various known pressures may answer this and other important questions definitely. The changes observed in partial-current curves as the vapor density is increased indicate that Akesson's assumption is not necessary to explain the facts; but no crucial test has yet been made.

\section{APPARATUS}

The difficulties in experiments with calcium and lead arise largely from the high temperature necessary for vaporization. The lead was heated to about $1050^{\circ} \mathrm{C}$ and the calcium to about $950^{\circ} \mathrm{C}$; but the latter metal is more difficult to handle on account of the chemical action of its vapor on quartz or porcelain.

The vacuum tubes were about $3 \mathrm{~cm}$ in diameter and $35 \mathrm{~cm}$ long, closed at the bottom, and with a brass plate which supported the electrodes sealed in the top. The grid was a cylinder of iron gauze about half the diameter of the tube, the outer electrode usually a short cylinder of thin sheet steel of nearly the diameter of the tube. These were supported by iron rods sealed in the top plate while the cathode was suspended from a ground glass joint.

A successful experiment with calcium was made with a fused quartz tube and electrodes as described above, but the condensed calcium stuck to the quartz and broke it when the tube cooled. Further experiments were made with a tube of glazed porcelain, and an inner protecting tube of thin steel fitting the porcelain tube snugly and reaching nearly to the top. This tube served as the outer electrode, and at the same time protected the porcelain from the hot calcium. Porcelain tubes with outer electrodes of the type first described were satisfactory for lead.

The greatest difficulty at high temperature is the large electric leak due to emission of electricity from the plate and grid. The only remedy is to employ relatively large electron currents. With calcium we used a hot wire cathode consisting of a loop of molybdenum wire coated with calcium oxide. This was welded to slightly larger tungsten leads run through pyrex-glass insulating tubes to avoid short-circuiting by condensing calcium. A similar electron source was tried in lead, but an equipotential surface gave much better results. A tube of sheet steel $6 \mathrm{~mm}$ in diameter coated with calcium oxide served as the surface. This fitted over a thin-walled porcelain tube in which a heating coil of molybdenum was mounted.

Current was measured on a shunted galvanometer with sensibility ranging from $1 \mathrm{O}^{-8}$ to $\mathrm{IO}^{-5}$ amperes per $\mathrm{mm}$. 
The lower part of the containing tube was heated in a tube resistance furnace wound with chromel wire, while its top was water cooled. The space between the ionization chamber and furnace tube was filled with sand to make the rate of cooling small when the heating circuit was broken, as was necessary while observations were being taken. Temperature was measured by a thermocouple in the sand.

The vacuum was maintained by glass mercury-vapor pumps of the type designed by one of the authors. ${ }^{4}$ With lead in the vacuum tube at $1000^{\circ} \mathrm{C}$ the gas pressure was never less than $0.002 \mathrm{~mm}$, but with calcium very high vacua were easily obtained. Gas was rapidly evolved until a temperature of about $600^{\circ} \mathrm{C}$ was reached, but above this point the gas was absorbed by the calcium and the pressure dropped quickly to less than $0.000 \mathrm{Im}$.

\section{OBSERVATIONS.}

Fig. I gives some of the curves of partial and total current versus accelerating potential in lead vapor. Curves $4, \mathrm{I} 4,20,26$ are total current, and curves I, 3, I0, 19, 23 partial current reaching the outer electrodes. In Table I are given the results from i 9 partial-current curves and 12 total-current curves.

The results from all the curves in which the inflections were sharp enough for measurement are tabulated, and the curves in the figure are typical. The total current showed ionization when the temperature reached $900^{\circ} \mathrm{C}$, but most of the data were obtained in the range 950 to $1050^{\circ} \mathrm{C}$. Through a window in the top plate of the vacuum tube it was possible to observe the arc at potentials above the ionization point. The arc was blue in color, due, probably, to the line $\lambda=4058 \ddot{A}$.

Fig. 2 gives typical curves of total and partial current in calcium vapor. Curves 8,18 , and 22 are total current, and curves I, 3, 9, I4, and I 5 partial current. In Table 2 the points of inflection in I I total-current curves and I I partial-current curves are given.

Some vaporization was visible at $600^{\circ} \mathrm{C}$, and the ionization point showed at $700^{\circ} \mathrm{C}$. The curves were obtained between 800 and $900^{\circ} \mathrm{C}$. The pressure was very low except in the case of curve 9, when the pump was stopped and a pressure of $0.02 \mathrm{~mm}$ was reached. The similarity of this curve to the others shows that when the metal is vaporizing rapidly traces of gas do not affect the results. The gas is cleaned out of the hot part of the tube by the current of vapor to an extent far in excess of the indicated gas pressure. 


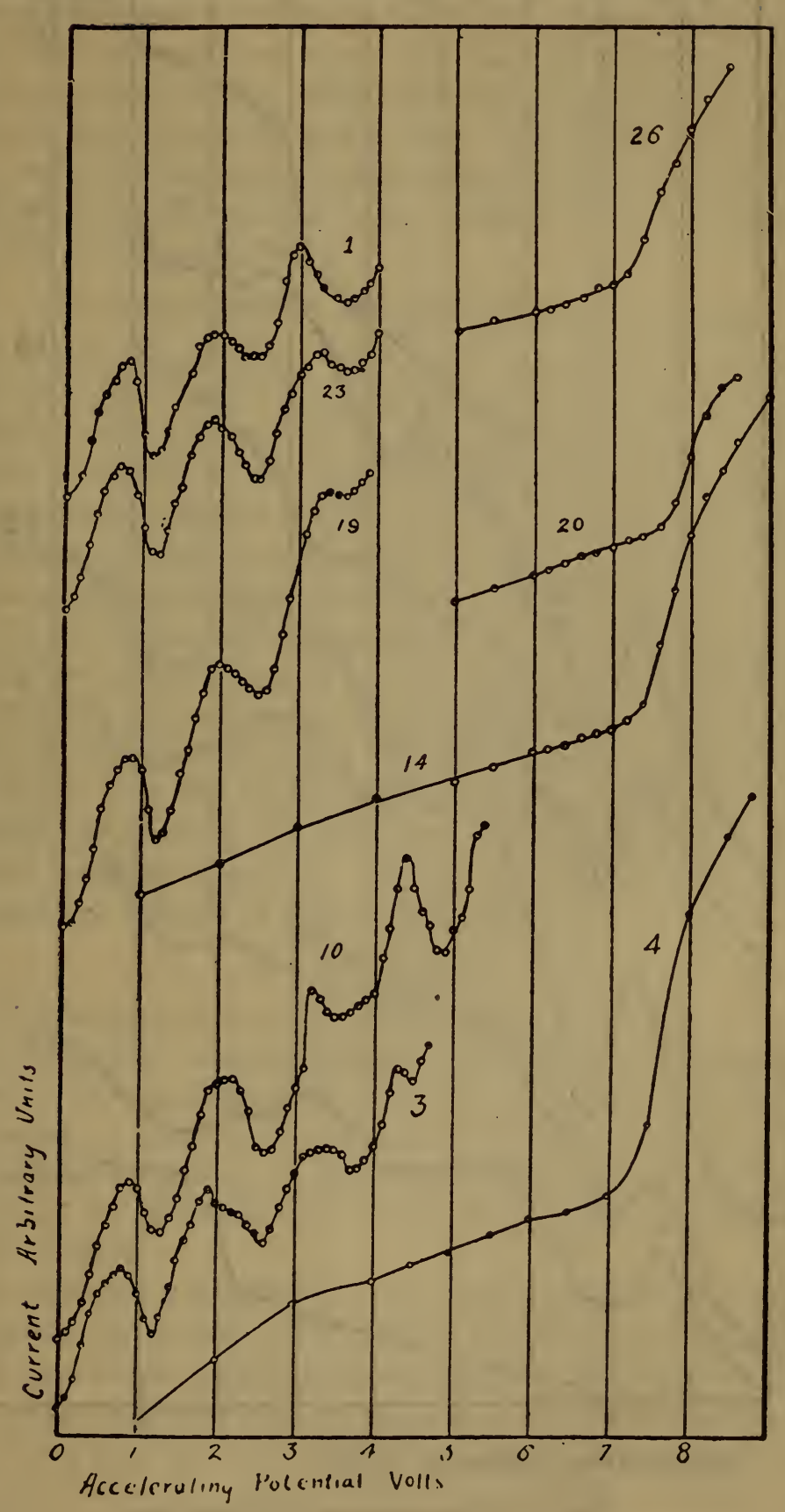

FIG. I.-Electron currents in lead vapor

Curves 4, 14, 20, and 26 "total current"; curves $x_{1} 3,10,19$, and 23 " partial current." 


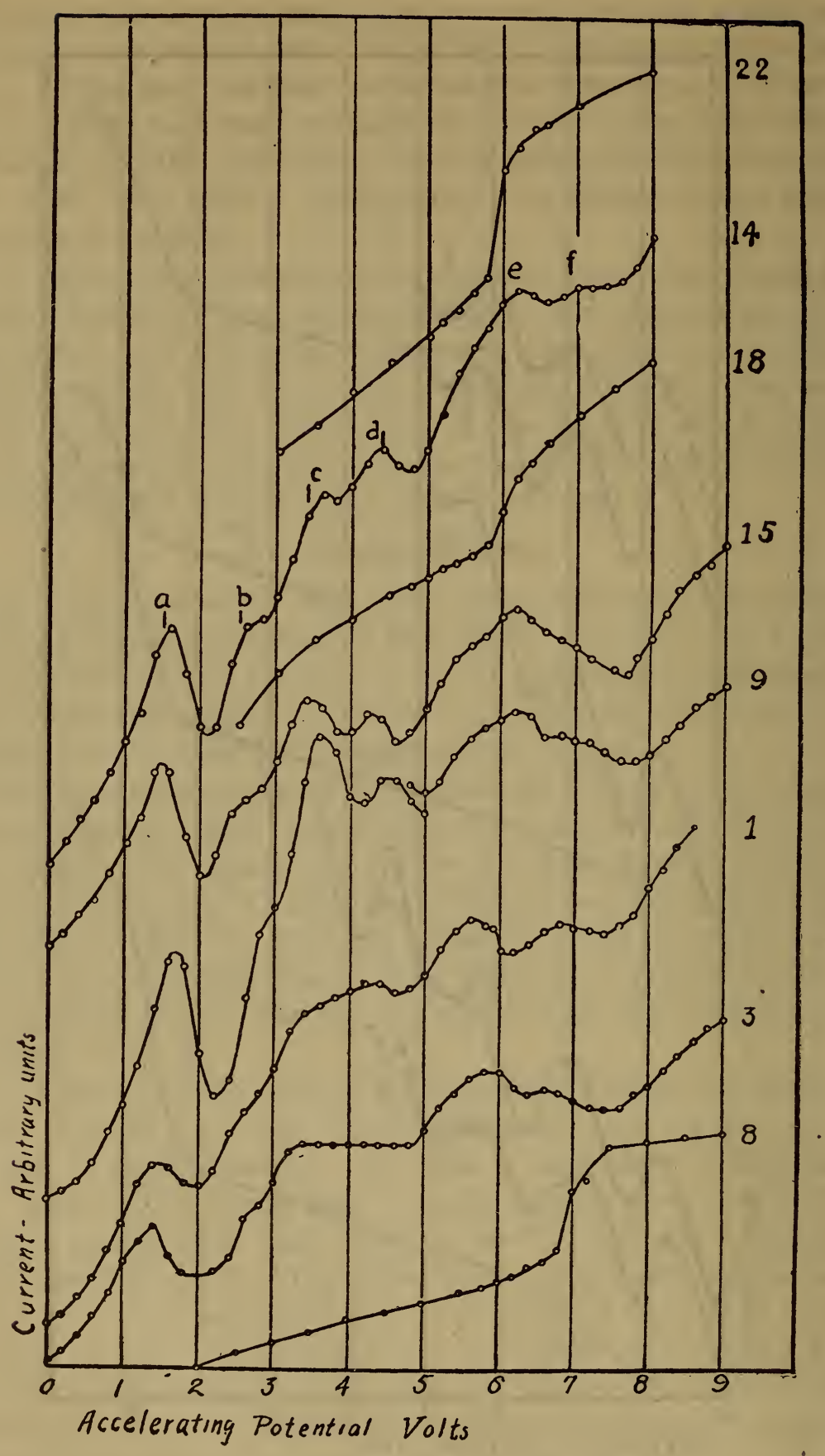

FIG. 2.-Electron currents in calcium vapor

Curves 8, 18, and 22 "total current"; curves $1,3,9$, I4, and 15 "partial current". 
As already noted, the current in lead was obtained from an equipotential source, while in calcium an incandescent wire was used. The current from a hot wire does not approach saturation in this range of voltage, while with an equipotential source saturation is approached with a few volts. This is the chief advantage of an equipotential surface when inelastic impact occurs at a low voltage. The difference in type of the two sets of curves is in part explained by this fact.

\section{DISCUSSION OF RESULTS WITH LEAD}

The points of inflection in the current-voltage curves for lead shown in Table $x$ give a mean value of 1.26 volts for the resonance potential and 7.93 volts for the ionization potential. The initial velocity correction to be added to the applied potential to give the ionization potential is taken in each case from the preceding or following partial-current curve, as varying conditions change this correction noticeably during the observations.

No series relations have been found as yet in the lead spectrum, nor is there anything known of fundamental frequencies in any of the metals in this column of the periodic table. In metals previously studied the quantum relation $V e=h \nu$ has been found to hold where $V$ is the resonance or ionization potential, $\nu a$ fundamental frequency in the spectrum, $e$ the electron charge, and $h$ Planck's constant of action. Taking $e=4.774 \times 10^{-10}, h=6.547 \times$ $\mathrm{IO}^{-27}$, and the velocity of light $=2.999+1 \mathrm{O}^{10}$,

$$
\lambda=\mathrm{I} 2334 / V
$$

when $V$ is measured in volts and $\lambda$ in Ångstrom units.

The value of $V$, corresponding to the resonance potential, is the frequency of a prominent spectrum line, the first line of a principal series or combination series in the metals so far studied. The limiting frequency of this series gives the value of $\nu$, corresponding to the observed ionization potential, except in the case of thallium.

The resonance potential $V=1.26$ volts makes $\lambda=9800 \AA$, with a possible error of $800 \AA$ or o.I volt. The single-line spectrum of lead, if such exists, should be in this region. Thermopile measurements of the lead spectrum by Randall ${ }^{5}$ show an isolated group of strong lines near this point and the shortest wave-length line of the group $\lambda=10291$ agrees with our prediction within experimental error. 
TABLE 1.-Resonance and Ionization Potentials in Lead

\begin{tabular}{|c|c|c|c|c|c|c|c|c|c|c|}
\hline \multirow{3}{*}{ Curve } & \multicolumn{5}{|c|}{ Applied potentials } & \multirow{2}{*}{\multicolumn{3}{|c|}{ Resonance potential }} & \multirow{3}{*}{$\begin{array}{l}\text { Initial } \\
\text { velocity }\end{array}$} & \multirow{3}{*}{$\begin{array}{l}\text { Ioniza- } \\
\text { tion po- } \\
\text { tential }\end{array}$} \\
\hline & \multicolumn{4}{|c|}{ At resonance } & \multirow{2}{*}{$\begin{array}{c}\text { At } \\
\text { ioni- } \\
\text { zation }\end{array}$} & & & & & \\
\hline & a & b & c & d & & b-a. & $c-b$ & d-c & & \\
\hline $1 .$. & 0.4 & 1.65 & 2.9 & & & 1.25 & 1.25 & & 0.86 & \\
\hline $2 \ldots$ & ...... & ........ & ....... & & 6.8 & ........ & $\cdots$ & & & 7.66 \\
\hline $3 .$. & .4 & 1.7 & 3.1 & 4.2 & ........ & 1.3 & 1.4 & 1.1 & .86 & \\
\hline $4 \ldots$ & .... & …. & $\cdots \cdots$ & & 6.8 & . & '.... & & & 7.66 \\
\hline $5 \ldots$ & .7 & 1.9 & 3.3 & & $\ldots \ldots$ & 1.2 & 1.4 & & .56 & \\
\hline $6 \ldots$ & .... & $\cdots$ & $\ldots$ & & 7.4 & $\cdots$ & & & & 7.96 \\
\hline $7 \ldots$ & .7 & 2.0 & 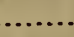 & & ...... & 1.3 & & & .56 & \\
\hline $8 \ldots$ & .6 & 1.9 & & & n......... & 1.3 & $\cdots$ & & .66 & $\cdots$ \\
\hline $9 . .$. & .... & $\ldots \ldots \ldots$ & $\ldots \ldots$ & & 7.6 & $\cdots \cdots$ & & & ..... & 8.26 \\
\hline $10 \ldots$ & .6 & 1.85 & 3.2 & 4.4 & ........ & 1.25 & 1.35 & 1.2 & .66 & ......... \\
\hline $11 \ldots$ & ..... & $\ldots \ldots$. & ....... & Pres & 7.2 & ...... & [..... & & & 8.01 \\
\hline $12 \ldots$ & .45 & 1.8 & 3.05 & 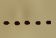 & $\ldots . .$. & 1.35 & 1.25 & ..... & .81 & \\
\hline $13 . .$. & .45 & 1.6 & 2.8 & 4.1 & .......... & 1.15 & 1.2 & 1.3 & .81 & $\ldots$ \\
\hline $14 \ldots$ & ..... & ..... & .... & & 7.2 & & & & & 7.99 \\
\hline $15 \ldots$. & .5 & 1.6 & ......... & & . & 1.1 & ........ & & .76 & \\
\hline $16 \ldots .$. & .5 & 1.9 & 3.2 & & ........... & 1.4 & 1.3 & & .76 & \\
\hline $17 \ldots$ & ..... & ......... & . . . . . . & & 7.2 & $\ldots \ldots$ & .......... & & & 7.96 \\
\hline $18 \ldots$ & .5 & 1.8 & 3.0 & & $\ldots$ & 1.3 & 1.2 & & .76 & 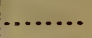 \\
\hline $19 \ldots$. & .5 & 1.8 & 3.2 & & $\ldots \ldots$ & 1.3 & 1.4 & & .76 & . \\
\hline $20 \ldots$. & .... & ........ & ....... & & 7.4 & ..... & ..... & & & 8.16 \\
\hline $21 \ldots .$. & .4 & 1.6 & 2.7 & $\ldots$ & ......... & 1.2 & 1.1 & ..... & .86 & . \\
\hline $22 \ldots$ & .4 & 1.5 & 2.7 & 4.0 & $\ldots \ldots$ & 1.1 & 1.2. & 1.3 & .86 & .......... \\
\hline $23 . . .$. & .5 & 1.6 & 3.0 & 4.3 & .......... & 1.1 & 1.4 & 1.3 & .76 & ......... \\
\hline $24 \ldots$. & $\cdots$ & ..... & ..... & ..... & 7.2 & & & & & 7.96 \\
\hline $25 \ldots$. & .4 & 1.6 & 2.9 & 4.2 & .......... & 1.2 & 1.3 & 1.3 & .86 & ......... \\
\hline $26 \ldots$ & ..... & $\ldots \ldots$ & ..... & ..... & 6.7 & ...... & ....... & ... & $\cdots$ & 7.66 \\
\hline $27 \ldots$ & .2 & 1.35 & 2.8 & 4.0 & $\ldots \ldots \ldots$ & 1.15 & 1.45 & 1.2 & 1.06 & ......... \\
\hline $28 \ldots$ & ... & ..... & & & 6.8 & ..... & & & & 7.86 \\
\hline $29 . \ldots$. & .1 & 1.3 & 2.6 & & $\ldots \ldots \ldots$ & 1.2 & 1.3 & & 1.16 & .......... \\
\hline $30 \ldots$ & $\cdots$ & & & & 7.0 & .......... & ........ & & & 8.16 \\
\hline $31 \ldots$ & .1 & 1.3 & 2.6 & 3.9 & ........ & 1.2 & 1.3 & 1.3 & 1.16 & ........... \\
\hline
\end{tabular}

Mean resonance potential, 1.26 volts.

Mean ionization potential, 7.93 volts.

The ionization potential corresponds to $\lambda=1550$. This may be the limit of a series of which $\lambda=1029 \mathrm{I}$ is the first line; but it is noticeable that the frequency ratio between the first line and limit of such a series would be much greater than in the usual type. In nearly all known series the ratio of frequencies is between 2 and 3 while this is nearly 7 . In the case of thallium alone we found that ionization was not determined by the limit of a principal series; but our results have shown that there is little basis for reasoning by analogy when we are dealing with metals in different columns of the periodic table. If $\lambda=1029 \mathrm{I}$ is the singleline spectrum, we are able to compute an accurate value for the resonance potential. The above data thus give $V=1.198$ volts. 


\section{DISCUSSION OF RESULTS WITH CALCIUM}

In Table 2 is presented a summary analysis of the curves obtained with calcium vapor. The tabulation of these inflectional points in the partial-current curves appears to indicate a resonance potential of about $\mathrm{I}$ volt, but inspection of the curves on Fig. 2 shows that strong inflections occur at 2 -volt intervals with less marked, intermediate inflections. Such curves may be explained by the existence of 2 resonance potentials.

TABLE 2.-Resonance and Ionization Potentials in Calcium

\begin{tabular}{|c|c|c|c|c|c|c|c|c|c|c|c|}
\hline \multirow{2}{*}{ Curve } & \multicolumn{6}{|c|}{ Applied potentials at resonance } & \multirow{2}{*}{$\begin{array}{c}\text { At } \\
\text { ioni- } \\
\text { zation }\end{array}$} & \multicolumn{2}{|c|}{$\begin{array}{l}\text { Resonance } \\
\text { potentials }\end{array}$} & \multirow{2}{*}{$\begin{array}{l}\text { Initial } \\
\text { velocity }\end{array}$} & \multirow{2}{*}{$\begin{array}{c}\text { Ioni- } \\
\text { zation } \\
\text { poten- } \\
\text { tial }\end{array}$} \\
\hline & a & b & c & d & e & 1 & & $\underset{c-a}{\text { First }}$ & $\begin{array}{c}\text { Second } \\
\mathrm{d}-\mathrm{a}\end{array}$ & & \\
\hline 1.. & 1.4 & 2.4 & 3.2 & 4.2 & 5.2 & 6.8 & & 1.8 & 2.8 & 0.5 & \\
\hline 2.. & & & & $\cdots$ & & & 5.5 & & & & 6.0 \\
\hline 3.. & 1.4 & 2.6 & 3.2 & ..... & 5.2 & 6.6 & & 1.8 & & .5 & \\
\hline 4.. & $\ldots$ & $\cdots$ & .... & $\ldots$ & .... & .... & 5.6 & .... & & ... & 6.1 \\
\hline 5.. & $\ldots$ & $\cdot$ & ..... & ..... & .... & ..... & 5.5 & .... & ... & ... & 6.0 \\
\hline $6 .$. & 1.6 & ...... & 3.2 & 4.4 & 5.6 & 6.6 & ..... & 1.6 & 2.8 & .3 & .... \\
\hline 7.. & 1.4 & 2.6 & 3.6 & 4.6 & & & ..... & 2.2 & 3.2 & .5 & .... \\
\hline 8.. & ..... & ..... & ..... & ..... & ... & ...... & 6.0 & & & .... & 6.5 \\
\hline 9.. & 1.5 & 2.8 & 3.5 & 4.4 & 5.5 & 6.8 & ..... & 2.0 & 2.9 & .4 & .... \\
\hline $10 .$. & .... & … & … & $\ldots$. & & $\ldots$. & 5.5 & $\cdots$ & $\cdots$ & .... & 5.9 \\
\hline $11 .$. & & ..... & ..... & ..... & & .... & 5.8 & & ..... & .... & 6.2 \\
\hline $12 .$. & 1.6 & 2.6 & 3.6 & 4.2 & 5.6 & 6.2 & ....... & 2.0 & 2.6 & .3 & $\ldots$ \\
\hline $13 \ldots$ & 1.4 & 2.4 & 3.3 & 4.2 & ..... & ...... & ...... & 1.9 & 2.8 & .5 & ........ \\
\hline $14 .$. & 1.5 & 2.5 & 3.4 & 4.4 & 5.8 & 6.8 & ...... & 1.9 & 2.9 & .4 & ......... \\
\hline $15 \ldots$ & 1.4 & 2.4 & 3.3 & 4.2 & 5.4 & 6.2 & ...... & 1.9 & 2.8 & .5 & .... \\
\hline $16 \ldots$ & $\cdots$ & ...... & $\ldots$. & $\cdots$ & $\cdots$ & $\cdots$ & 5.6 & & & & 6.1 \\
\hline $17 .$. & 1.4 & 2.4 & 3.3 & 4.3 & 5.4 & 6.6 & ...... & 1.9 & 2.9 & .5 & $\ldots$ \\
\hline $18 .$. & & & 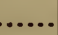 & & & $\cdots$ & 5.4 & & & & 5.9 \\
\hline $19 .$. & $\ldots$ & .... & $\ldots$ & 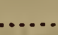 & 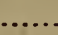 & $\ldots$ & 5.4 & & & $\ldots$ & 5.9 \\
\hline $20 .$. & 1.5 & 2.4 & 3.4 & 4.3 & 5.4 & 6.5 & ..... & 1.9 & 2.8 & .4 & .... \\
\hline 1 & & 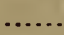 & & & .... & $\cdots$ & 5.3 & & & $\ldots$ & 5.7 \\
\hline 22. & & & & & & & 5.4 & & & & 5.8 \\
\hline
\end{tabular}

Mean resonance potentials, 1.90 volts and 2.85 volts.

Mean ionization potential, 6.01 volts.

In order to illustrate this fact, we shall anticipate our results to the extent of postulating that two types of inelastic impact without ionization may take place in calcium vapor, type $\mathbf{r}$, in which the colliding electron loses r.877 volts velocity, and type 2 , in which 2.918 volts velocity is lost. Collisions of type $\mathrm{I}$ are somewhat more probable than those of type 2 . Up to a maximum loss in velocity of 7 volts the following table represents the possible permutations with these two types of collision. The corresponding total loss in velocity after each successive collision is given in columns 2 to 4 . 
TABLE 3.-Velocity Losses in Calcium

\begin{tabular}{|c|c|c|c|}
\hline Type of collision & $\begin{array}{c}\text { First } \\
\text { Impact }\end{array}$ & $\begin{array}{l}\text { Second } \\
\text { impact }\end{array}$ & $\begin{array}{l}\text { Third } \\
\text { impact }\end{array}$ \\
\hline (1) (1) (1)... & $\begin{array}{l}\text { Volts } \\
1.877\end{array}$ & $\begin{array}{ll}\text { Volts } \\
\quad 3.754\end{array}$ & $\begin{array}{l}\text { Volts } \\
5.631\end{array}$ \\
\hline (1) (2) (1)... & 1.877 & 4.795 & 6.672 \\
\hline (2) (1) (1)... & 2.918 & 4.795 & 6.672 \\
\hline (1) (1) (2)... & 1.877 & 3.754 & 6.672 \\
\hline (1) (2)....... & 1.877 & 4.795 & $\ldots$ \\
\hline (2) $(1), \ldots \ldots \ldots \ldots \ldots, \ldots$ & 2.918 & 4.795 & ..... \\
\hline (2) (2) $\ldots \ldots \ldots \ldots \ldots \ldots$ & 2.918 & 5.836 & $\cdots$ \\
\hline
\end{tabular}

Since collisions of type I are more probable, we should expect that the velocity losses of 1.88 volts would show prominently on the partial-current curves. A loss of 2.92 volts resulting from the less probable collision of type 2 should appear less prominently. Similarly, two collisions of type I are more probable than two of type 2 or one of each type, and hence the point 3.75 should be more pronounced than the point 4.80 . From 5.6 to 5.8 the effects of two collisions of type 2 and of three collisions of type I are superposed, and above this point two collisions of type I and one of type 2 causes an inflection in the curve at 6.67 volts. As the velocity is still further increased the various permutations overlap and the true inflectional points are obscured. The prominence attained by different portions of the curves depends upon the vapor density, since with very attenuated vapor the probability of two or more collisions of any type may be exceedingly small. The curves of Fig. 2 confirm the above deductions.

If the average values of the successive points $a, b, c$, etc., of Table 2 are corrected by the average initial potential, we obtain a composite curve which may be compared with the values to be expected from Table 2 on the basis of the above assumption as follows:

TABLE 4.-Velocity Losses in Calcium

\begin{tabular}{|c|c|c|c|c|c|}
\hline & Observed & Theoretical & -1 & Observed & Theoretical \\
\hline a.. & $\begin{array}{l}\text { Volts } \\
\quad 1.88\end{array}$ & $\begin{array}{l}\text { Volts } \\
\quad 1.88\end{array}$ & d........... & $\begin{array}{l}\text { Volts } \\
4.74\end{array}$ & ${ }_{4.80}^{\text {Volts }}$ \\
\hline 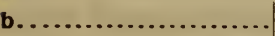 & 2.93 & 2.92 & e...... & 5.84 & 5.6 to 5.8 \\
\hline 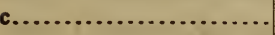 & 3.78 & 3.75 & t. $\ldots \ldots \ldots \ldots$ & 6.9 & 6.67 \\
\hline
\end{tabular}

Most of the curves given show six points of inflection, but point $b$ is always very faint and points $e$ and $f$ vary both in position and distinctness. As the latter points are above the ionization potential, this gives rise to an effect varying with the vapor pressure which makes current readings unreliable. For these 
reasons the two resonance potentials and initial velocity-corrections were computed from the points $a, c$, and $d$. Thus, in curve I $4, a$ is at $\mathrm{I} .5$ volts; $c$ at 3.4 ; and $d$ at 4.4 , giving the first resonance potential, $c-a, \mathrm{I} .9$ volts; the second, $d-a, 2.9$ volts; and the initial velocity, 0.4 volt.

Computed in this manner the mean values from the data in Table 2 are principal resonance potential I.90 volts, secondary resonance potential 2.85 volts, ionization potential 6.01 volts.

The occurrence of two resonance potentials has been suspected in the case of other metals, notably zinc and magnesium; but this is the first instance in which the phenomena were unmistakable. It suggests the possibility that in all metals there may be many potentials of inelastic impact of which the observed potential is the most probable.

The chief purpose of the authors in making these measurements in calcium vapor was to find the frequencies of the spectrum which correspond to the resonance and ionization potentials in the quantum relation $V e=h \nu$ or $V=\frac{12334}{\lambda}$. Previous work shows that spectral relations are similar among metals in the same group of the periodic table. Spectra of elements in the second column are characterized by three groups of series; single line, doublet and triplet series, and combination series lines, of which combinations of single line and triplet terms are prominent. The frequency of the combination line I.5 $S-2 p_{2}$ has been shown to give the resonance potential and the frequency $1.5 S$ the ionization potential in the case of all these metals previously studiednamely, zinc, cadmium, mercury, and magnesium. The first line of the principal series of single lines $1.5 S-2 P$ is, however, predominant in the spectra of magnesium, calcium, strontium, and barium and strong in all the metals of this group.

The limit of the principal series of single lines ${ }_{1.5} S$ in the calcium spectrum is computed by F. A. Saunders ${ }^{6}$ to be $\nu=49304.8$, $\lambda=2027.56$. As this is based on better data, it is to be preferred to the number deduced by Lorenser. This gives $V=6.08 \mathrm{I}$ volts in close agreement with the observed value $V=6.01$ volts.

The line r.5 $S-2 p_{2}$ has not been correctly identified in any published work. Using Saunders's value of 1.5 $S$ and Dunz's value of $2 p_{2}, \nu=34089.47,1.5 S-2 p_{2}=15215.33$. There is a calcium line at $\lambda=6572.78$. $\frac{1}{\lambda}=15210.3$ in vacuum. This agreement is 
good, for the limiting frequency $1.5 S$ is difficult to determine, as is shown by the various results of different authorities. Physical properties of this line make its identification almost certain, although it is apparently insignificant in arc or spark spectra. The wave length $\lambda=6572.78$ corresponds to $V=1.877$ volts, while the observed value is $V=1.90$ volts.

The first line of the principal series $1.5 S-2 P$ is $\lambda=4226.73$, giving $V=2.918$ in good agreement with the observed secondary resonance potential $V=2.85$ volts.

These results add importance to the study of the relative intensity of the lines $\mathrm{r} .5 S-2 p_{2}$ and $\mathrm{r}_{5} S-2 P$ in spectra of metals of this group under different modes of excitation. Following the discovery by Franck and Hertz ${ }^{7}$ that mercury vapor, when bombarded by electrons with velocity equal to the resonance potential, emitted the line I.5 $S-2 p_{2}(\lambda=2537)$ alone or at least predominantly. McLennan ${ }^{8}$ made similar observations on low voltage arcs in cadmium, zinc, and magnesium. In cadmium and zinc the results were analogous to mercury, but in magnesium the line I. $5 S-2 P$ alone was observed below the ionization potential. $\mathrm{He}$ concluded that the frequency I.5 $S-2 p_{2}$ was fundamental in zinc, cadmium, and mercury, and $1.5 S-2 P$ in magnesium, calcium, strontium, and barium.

Davis and Goucher, ${ }^{9}$ by their ingenious method of detecting the appearance of different types of radiation from the photoelectric effect, showed that in mercury vapor radiation occurred with 4.9 volts accelerating potential corresponding to $\lambda=2537$ and increased at 6.7 volts corresponding to the first line of the principal series $\lambda=1849$.

Later McLennan and Ireton ${ }^{10}$ showed by spectroscopic methods that in zinc and cadmium the first line of the principal series appeared at potentials corresponding to their respective frequencies.

The Davis and Goucher experiment is entirely different in principle from the method used by Franck and Hertz to detect the potential of inelastic impact in mercury and used by us in our work. The curves obtained by Franck and Hertz ${ }^{11}$ are beautifully regular and show only one resonance potential.

Our measurements show that the frequency $I_{5} S-2 p_{2}$ is of predominant importance in determining inelastic impact in all

\footnotetext{
7 Verh. der Deut. Phys. Ges., 16, p. 512; 1914.

8 Proc. Roy. Soc., 91, p. 485; 92, p. 307; 92, p. 574; 1915-16.

9 Phys. Rev., 10, p. 101; 1917.

10 Phil. Mag., 36, p. $46 \mathrm{r}$; 1918.

11 Verh. der Deut. Phys. Ges., 16, p. 457; r914.
} 
the metals of this group which we have studied, although the frequency $1.5 S-2 P$ is also effective in calcium, and possibly magnesium. The relation between low-voltage arc lines and potentials of inelastic collision is evidently complicated.

McLennan has made no observations of the low-voltage arc in calcium. An experiment performed in this laboratory by $\mathrm{Dr}$. Meggers and one of the authors indicates that the line ${ }_{1} \cdot{ }_{5} S-2 P$ $(\lambda=4227)$ does appear below the ionization potential.

The evidence is based on a purely accidental result of a spectro. scopic study of low-voltage arcs in cæsium vapor. Several photographs of the arc spectrum, with an applied potential of 2.2 volts, showed a line which in all probability was the 4227 line of calcium. As the dispersion was very small, the evidence is not certain, but the cæsium was made by heating cæsium chloride in calcium so the occurrence of calcium or calcium chloride was not unlikely. The fact that the line appeared with an applied voltage less than the secondary resonance potential, 3 volts, may not be important, for the actual potential may have been as much as I volt higher than the applied potential.

Interesting light on these fundamental frequencies in the spectra of calcium and magnesium is given by the work of A. S. King ${ }^{12}$ on spectra in the vacuum tube furnace at different temperatures. The contention of Hemsalech ${ }^{13}$ that spectra observed in tube furnaces are at least in part low-voltage arcs may be significant, for if this is true low-temperature spectra are low-voltage spectra.

In the calcium spectrum at high temperature the line $\lambda=4227$ is predominant and $\lambda=6573$ quite faint, while at low temperature $\lambda=4227$, though still the brightest line, has lost considerably in relative brightness, and $\lambda=6573$ has increased until it is second only to $\lambda=4227$. Magnesium shows the same phenomena. The wave length $\lambda=285^{2}$, which is the first line of the principal series, is predominant at high temperature, while $1.5 S-2 p_{2}(\lambda=457 \mathrm{I})$ is faint; but at low temperature in this case $\lambda=457 \mathrm{I}$ is the brightest line in the spectrum and $\lambda=285^{2}$ has entirely disappeared.

.Whether tube-furnace spectra are due to thermal emission or low-voltage arcs, the change in the spectra as the temperature is varied offers a means of differentiating the fundamental frequencies in other elements.

From the combined results of experiments on the metals of the second group of the periodic table the following conclusions can 
be drawn: Inelastic collision in all these metals occurs at a potential corresponding to the spectral frequency $r_{5} S-2 p_{2}$. In calcium, and probably in some other metals of the group, there is a second resonance potential given by the line I.5S-2P. The ionization potential is in all cases determined by the frequency I.5S. Arcs with voltage less than the ionization potential in zinc, cadmium, and mercury show the line $1.5 S-2 p_{2}$ predominantly, while magnesium, and probably all the alkali earth metals, shows I.5 $S-2 P$ predominantly. The line ${ }_{1} .5 S-2 P$ probably appears in spectra of all metals in this group below the ionization potential.

The evidence of the proportionality between potentials of inelastic collision and spectral frequency is now so extensive as to be beyond question. However, the assumption that all electron collisions of one type give rise to one spectral line does not seem to explain the relative intensity of the two lines $1.5 S-2 P$ and I. $S-2 p_{2}$ below the ionization potential. The tube-furnace spectra, for instance, show at least that the two emission centers are affected differently by a change in physical condition, whether it is the temperature or the electric field that plays the important part.

\section{SUMMARY}

The resonance and ionization potentials in lead vapor are at I. 26 and 7.93 volts, respectively. The line $\lambda=1029 \mathrm{I}$ is probably related by the quantum equation to the resonance potential. This gives a theoretical value of 1.198 volts for the resonance potential.

Measurements in calcium vapor show two resonance potentials, I.90 volts and 2.85 volts, the former of which is most pronounced. The observed value of the ionization potential is 6.0 r volts.

The first resonance potential is determined by the frequency I. $5 S-2 p_{2}(\lambda=6572.78)$. The theoretical value is $\mathrm{I} .877$ volts.

The second resonance potential is related to the first line of the principal series, I.5 $S-2 P(\lambda=4226.73)$, giving the theoretical value 2.918 volts.

The limit of the principal series, $1.5 S(\lambda=2027.56)$, corresponds to the value $6.08 \mathrm{I}$ volts for the ionization potential.

The spectral relations of the first resonance potential and ionization potential are analogous to those previously found in other metals of this group in the periodic table.

WASHINGTON, October I, I9I9. 